\title{
Pembayangan Mandiri pada Material Bata Ringan di Iklim Tropis
}

\author{
Mochamad Hilmy', Dewi Ria Indriana ${ }^{1}$ \\ ${ }^{1}$ Program Studi Arsitektur Bangunan Gedung Politeknik Negeri Pontianak, Pontianak, Indonesia \\ mhilmys@gmail.com \\ doi.org/ 10.29080/emara.v4i1.222
}

\begin{abstract}
The purpose of this study was to obtained recommendations on the use of innovative building materials from the development of existing lightweight concrete designs, to decrease the building interior temperature. The research used an engineering experimental method on lightweight concrete as material tested. A profile was attached on the outer side of lightweight concrete in order to formed a shadowed effect and expected to make the building indoor temperature go lower. The result indicated that the shadows shaped by profile attached on the outer side of lightweight concrete not fully effectively in decreasing building indoor temperature. The lightweight concrete thickness affected the velocity of solar thermal radiation impact movement that goes into the buildings interior. The formation of profiles on lightweight concrete surfaces can be decrease the room temperature in at least more than $2^{\circ} \mathrm{C}$. The shading was more effective if the profile form in vertical formation. The research output was a lightweight concrete prototype that was able to contribute to decrease the building indoor temperature.
\end{abstract}

Keywords: lightweight brick, self shading, thermal

\begin{abstract}
Abstrak: Penelitian ini bertujuan untuk mendapatkan rekomendasi penggunaan material bangunan yang inovatif dari pengembangan desain bata ringan yang ada dalam upaya untuk menurunkan suhu ruang dalam di bangunan gedung. Metode yang digunakan dalam penelitian ini adalah eksperimen rekayasa kuatitatif terhadap material uji bata ringan. Perlakuan yang dimaksud adalah dengan pemberian profil pada permukaan sisi luar bata ringan sehinga diharapkan membentuk efek pembayangan dan menciptakan upaya penurunan suhu ruang dalam. Pembayangan tidak sepenuhnya efektif terhadap penurunan temperatur ruang dalam yang dikarenakan pembentukan profil pada permukaan bata ringan. Ketebalan bata ringan mempengaruhi kecepatan rambat pergerakan dampak radiasi panas matahari ke ruang dalam. Pembentukan profil pada permukaan bata ringan dapat menurunkan temperatur ruang dalam setidaknya lebih dari $2^{\circ} \mathrm{C}$. Pembayangan lebih efektif jika bentuk profil adalah vertikal. Luaran penelitian ini adalah berupa purwarupa bata ringan yang mampu memberikan kontribusi terhadap penurunan suhu ruang dalam bangunan.
\end{abstract}

Kata Kunci: bata ringan, pembayangan mandiri, termal

\section{PENDAHULUAN}

Krisis energi telah lama melanda di seluruh penjuru bumi. Berbagai upaya telah dilakukan baik dari peralatan yang menggunakan energi, sarana dan prasarana lain, lingkungan maupun dari sisi sosial budaya masyarakat. Dunia arsitektur merupakan salah satu yang berkontribusi pada masalah tersebut. Salah satu yang menjadikan penyebab munculnya penggunaan energi di dunia arsitektur adalah permasalahan kenyamanan termal yang mengganggu aktifitas manusia.

Di daerah iklim tropis, permasalahan berkaitan dengan kenyamanan termal adalah tingginya suhu udara baik di lingkungan maupun di dalam bangunan.
Permasalahan tersebut selama ini diatasi dengan penggunaan alat pengkondisian udara (Air Conditioner/ AC). Penggunaan AC yang berlebihan menimbulkan masalah baru, yaitu tidak mampunya PLN sebagai penyedia daya listrik, sehingga sering terjadi pemadaman listrik. Dalam menjalankan aktifitasnya, manusia menginginkan selalu mendapatkan kenyamanan. Emisi yang dihasilkan oleh bangunan baik secara langsung maupun tidak berkaitan dengan material bangunan dan energi yang digunakan selama kehidupan di dalam bangunan berlangsung. Atmosfir merupakan mesin pemanas raksasa berbahan bakar matahari, karena atmosfir tersebut transparan terhadap energi surya, maka 
pemanasan terjadi di permukaan bumi. Panas radiasi matahari tersebut berdampak pada bangunan gedung. Beberapa upaya untuk mengurangi dampak radiasi matahari di bangunan gedung, antara lain dengan sistem pembayangan. Pembayangan merupakan upaya yang paling efektif dilakukan pada bangunan tropis sejak bangunan vernakular dan tradisional. Hal ini menjadikan bangunan tropis memiliki teritisan bangunan untuk menciptakan pembayangan. Pada kasus masa kini, kecenderungan lahan yang semakin sempit dan trend desain yang "minimalis" menjadikan pembayangan yang dihasilkan dari teritisan atap sangat minim.

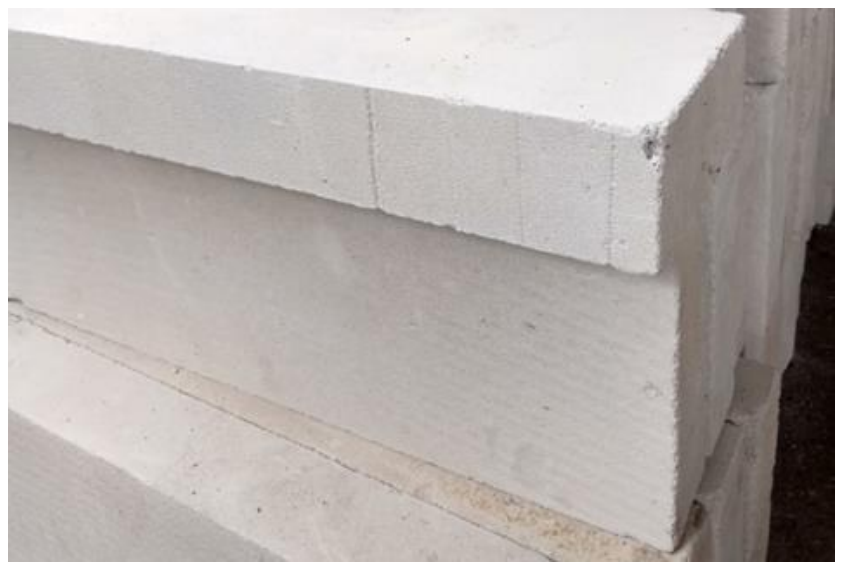

Gambar 1. Bata ringan (Sumber: dokumentasi peneliti, 2017)

Penggunaan bata ringan sebagai material bangunan yang diharapkan menjadi pilihan tepat untuk bangunan di lahan gambut. Produsen bata ringan menyatakan bahwa keunggulannya selain ringan adalah tahan panas dibandingkan material konvensional sebelumnya yaitu batako, namun penggunaan material semen yang menjadi bahan dasar bata ringan tetap berkontribusi menyalurkan radiasi panas matahari. Berdasarkan hal-hal tersebut, dirasa perlu dilakukan pengkajian terhadap efisiensi dan efektifitas desain bentuk material bata ringan dalam upaya untuk menurunkan suhu ruang dalam di bangunan gedung. Pemilihan material bata ringan didasarkan pada karakternya yang memiliki ketebalan yang memungkinkan dilakukan beberapa perlakuan guna mendapatkan desain yang diharapkan.

Sebuah kajian yang pernah dilakukan terhadap sistem pembayangan pada bangunan perumahan bergaya minimalis (Murtomo, 2008). Susanto et al., (2011) juga pernah melakukan pengkajian terhadap penggunaan dinding bata ringan dan kemampuan Foam Concrete (FC) untuk melakukan efisiensi energi dengan mempelajari kelayakannya sebagai pasangan dinding dari aspek mekanis dan termal. Kajian kali ini berusaha menggabungkan antara sistem pembayangan dan diterapkan pada bata ringan sebagai material yang mampu mereduksi radiasi matahari guna mencapai kenyamanan termal ruang dalam sebuah bangunan gedung. Kajian ini membatasi pada upaya pencapaian kenyamanan thermal dengan melakukan rekayasa pada bata ringan untuk mendapatkan pembayangan yang optimal. Pemilihan bata ringan juga karena bata ringan (CLC) memiliki daya serap air sebesar $25 \%$ di bawah beton pejal (Hunggurami, Bunganaen, \& Muskanan, 2014), sehingga diharapkan bata ringan ini dapat diekspos tanpa harus melakukan finishing yang akan mempengaruhi bentuk permukaan bata. Pengukuran suhu udara di ruang luar di Kota Pontianak dalam beberapa tahun terakhir rata-rata berkisar $33 \sim 38^{\circ} \mathrm{C}$ bahkan bisa mencapai $42^{\circ} \mathrm{C}$ pada siang hari hingga sore hari.

Kenyamanan termal dipengaruhi oleh kualitas kenyamanan termal, pemilihan jenis dan warna material selubung bangunan, serta luas material transparan (Prakoso, Lamahala, \& Sentanu, 2014). Foam concrete berbahan dasar semen-pasir dengan komposisi mortar berbanding foam sebesar 0,4:0,6 dapat menghemat energi operasional AC sebesar $59 \%-64 \%$ lebih rendah dibandingkan penggunaan bata konvensional. Foam concrete berbahan dasar semen-fly ash mampu menghemat energi operasional AC sebesar $40 \%$ dibandingkan dinding berbahan bata konvensional (Susanto et al., 2011). Material beton merupakan material thermal mass yang memiliki kemampuan menghambat perpindahan panas masuk ke dalam bangunan seperti halnya batu andesit transparan (Prakoso et al., 2014).

Suhu udara di luar akan ditransfer ke dalam bangunan gedung melalui selimut bangunan dan bentuk dan komposisi material dinding memiliki dampak yang berbeda terhadap suhu udara di dalamnya (Hilmy, 2016). Radiasi matahari dapat ditanggulangi dengan melakukan pembayangan. Hal ini dapat dilakukan dengan menggunakan penangkal sinar matahari berupa tritisan atau shading device, sehingga sinar matahari tidak langsung merambatkan panas pada dinding bangunan (Pagalla, Thojib, \& Sudarmo, 2013). Dinding akan menjadi panas apabila tidak terlindungi dari radiasi matahari dan akan meneruskan panas ini ke dalam ruangan. Pembayangan dinding sangat dibutuhkan untuk mengurangi panas yang disebabkan oleh radiasi matahari yang merambat ke dalam bangunan dari dinding yang tidak terbayangi. Bangunan sisi barat dan timur lebih membutuhkan pembayangan ekstra dibandingkan pada sisi utara dan selatan (Murtomo, 2008) Pengaruh pembayangan massa bangunan terhadap radiasi panas matahari pernah dilakukan pengkajian di ruang terbuka kawasan tropis yang terletak pada garis lintang $7^{\circ} \mathrm{LS}$, dengan metode simulasi komputer dan dari kajian tersebut menyatakan orientasi bangunan terhadap lintasan 
sinar matahari sangat mempengaruhi hasil dari pembayangan yang terbentuk (Dotulong, 2018). Rekomendasi yang disampaikan adalah dengan membentuk sudut $45^{\circ}$ akan memberikan efek pembayangan paling maksimal. Resistensi termal bahan bangunan juga pernah diukur dengan metode aliran kalor dalam lingkungan terkondisi oleh (Suhedi, 2014). Hasil pengukuran tersebut mendapatkan hasil bahwa bata ringan memiliki kemampuan resistensi terhadap termal tertinggi dibandingkan dengan beberapa material lain, yaitu sebesar $0,583 \mathrm{~m} 2 . \mathrm{K} / \mathrm{W}$.

Kajian ini dilakukan untuk mendapatkan rekomendasi penggunaan material bangunan yang inovatif dari pengembangan desain bata ringan yang ada dalam upaya untuk menurunkan suhu ruang dalam di bangunan gedung. Dengan demikian aspek manfaat dari penelitian ini adalah ditujukan bagi masyarakat luas agar dapat membantu dalam menciptakan suasana ruang yang memiliki suhu ruang dalam yang nyaman tanpa harus menggunakan peralatan tambahan untuk mencapai kenyamanan termal yang diharapkan. Penggunaan peralatan yang menggunakan energi yang dapat ditekan diharapkan mengurangi pengeluaran biaya yang harus ditanggung oleh masyarakat serta mengurangi penggunaan energi listrik. Hasil dari penelitian ini lebih diperuntukkan bagi masyarakat di lingkungan tropis yang memiliki suhu udara tinggi di lingkungannya.

Produsen material bangunan juga akan terbantukan dengan adanya pengkajian inovasi terhadap material ini guna memenuhi kebutuhan konsumen. Pembentukan profil permukaan material diharapkan dapat mengurangi jumlah bahan baku material, sehingga dapat menekan tingkat kebutuhan bahan. Hal ini diharapkan dapat menekan biaya produksi bata ringan. Dengan adanya material yang sesuai dengan kebutuhan masyarakat, diharapkan tingkat penjualan akan lebih meningkat.

Target luaran kajian ini adalah berupa purwarupa material bata yang dilakukan rekayasa yang optimal agar mampu membantu mengurangi tingkat suhu ruang dalam pada bangunan gedung. Dalam pengukuran suhu udara dapat dilakukan dengan penggunaan hot wire seperti halnya yang telah dilakukan dalam mencoba mengkaji tingkat konduktifitas pada bata magnesia (Saito, Kanematsu, \& Matsui, 2009).

\section{METODE PENELITIAN}

Kajian ini dilakukan dengan pengukuran prototipe hasil rekayasa bentuk bata ringan yang ada di lapangan pada bagian permukaan untuk mendapatkan data dan dilakukan analisa untuk mendapatkan komposisi yang dapat dijadikan bagian dari upaya pencapaian kenyamanan termal ruang dalam. Purwarupa dibuat di Kota Pontianak sebagai perwakilan daerah beriklim tropis basah. Purwarupa ini dibuat di tempat terbuka agar mendapatkan perlakuan dengan kondisi alami.

Rekayasa yang dimaksud adalah dengan pemberian profil permukaan sehingga diharapkan dapat memberikan efek pembayangan di permukaan bata ringan itu sendiri. Berdasarkan beberapa pertimbangan, penelitian ini dilakukan beberapa perlakuan yang memungkinkan. Perlakuan yang dilakukan adalah pembentukan profil di permukaan bata ringan pada bagian luarnya. Pembuatan profil yang dilakukan adalah bentukkan sederhana yang diharapkan tidak terpengaruh oleh perulangan dan memudahkan pelaksanaan di lapangan. Profil yang dipilih adalah alur takikan lurus (parit lurus).

Variabel bebas (independent) dalam penelitian ini adalah perlakuan komposisi alur profil permukaan bata baik ukuran maupun arahnya yang dibandingkan dengan kondisi aslinya. Ukuran yang alur profil dibatasi dengan 3 kombinasi komposisi yaitu kedalaman (d), lebar alur (w1) dan lebar permukaan luar (w2) profil. Hal tersebut dapat di lihat pada gambar 2. Rekayasa juga dilakukan terhadap posisi arah alur yaitu secara horizontal dan vertikal. Analisa dilakukan pada bentuk, dimensi dan posisi profil bata ringan yang dilakukan perlakuan yang dikaitkan dengan kondisi temperatur udara ruang dalam. Analisa terhadap bentuk pembayangan yang terjadi pada bata ringan setelah mendapatkan perlakuan juga menjadi bahan pertimbangan terhadap efektifitas perlakuan yang dilakukan.

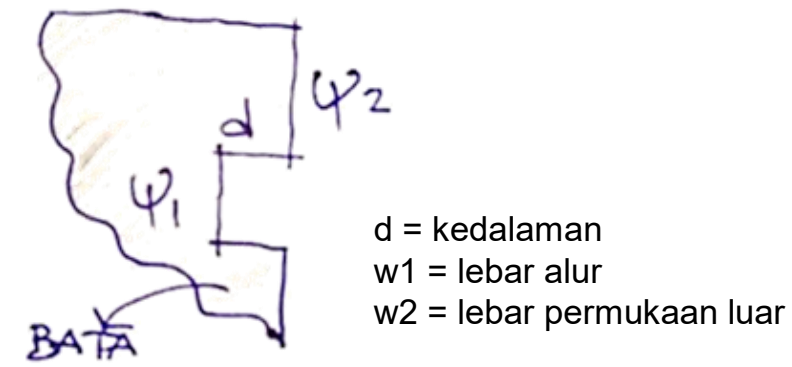

Gambar 2. Komposisi variabel bebas (Sumber: hasil olahan, 2017)

Ukuran yang dipilih untuk mendapatkan ukuran yang agak ekstrim namun memungkinkan dilakukan pada bata ringan tersebut. Lebar permukaan luar (w2) diperlakukan 2 ukuran yakni $3 \mathrm{~cm}$ dan $5 \mathrm{~cm}$. Bagian ini tidak dimulai dari $1 \mathrm{~cm}$ karena terlalu tipis dan mudah patah/ pecah. Lebar bagian dalam (w1) diperlakukan 3 ukuran yaitu $1 \mathrm{~cm}, 3 \mathrm{~cm}$ dan $5 \mathrm{~cm}$, sedangkan kedalaman (d1 dan d2) hanya diperlakukan $1 \mathrm{~cm}$ dan $3 \mathrm{~cm}$, karena ketebalan bata total hanya $7 \mathrm{~cm}$, sehingga jika diberikan kedalaman lebih dari setengah dikhawatirkan kekuatan bata itu sendiri akan hilang. Pengambilan data tersebut kemudian dimasukkan ke dalam tabulasi data temperatur yang telah disiapkan. Beberapa perbedaan pola pada beberapa waktu yang 
berbeda sepanjang hari. Pola terjadi pada waktu matahari terbit, siang dan menjelang sore (pukul 12:00-15:00), malam (pukul 18:00-21:00) dan tengah malam atau dini hari (Rampanelli, Zardi, \& Rotunno, 2004). Pada pukul 4 sore suhu ruang luar sangat tinggi (Lechner, 2014). Pengambilan data dilakukan dalam rentang waktu 3 bulan untuk dapat mewakili beberapa kondisi cuaca. Data yang diperlukan untuk mendapatkan variabel kenyamanan adalah suhu udara di lingkungan dan di dalam objek purwarupa. Hal ini penting dilakukan untuk mendapatkan faktor kenyamanan termal.

\section{HASIL DAN PEMBAHASAN}

\subsection{Pengukuran pada perlakuan bata ringan terhadap temperatur ruang dalam}

Berbeda dengan beberapa kajian yang telah dilaksanakan sebelumnya seperti yang telah dijelaskan di atas, dalam kaijan ini difokuskan pada efek dari pembentukan profil pada permukaan bata ringan terhadap temperatur udara ruang dalam. Ruang dalam yang dimaksud merupakan ruang dalam untuk fungsi hunian, karena di bangunan gedung tersebut sangat memerlukan adanya kenyamanan termal guna menunjang aktifitas manusia. Kondisi termal tentunya disesuaikan dengan iklim tropis.

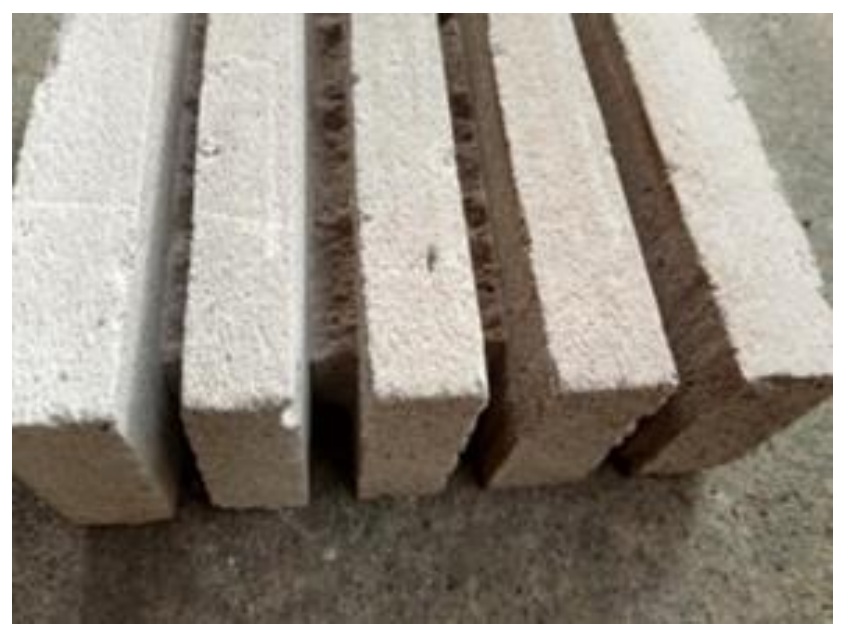

Gambar 3. Profil rekayasa bata (sumber: dokumentasi peneliti, 2017)

Hasil dari pengukuran dilakukan tabulasi data dan dilanjutkan dengan penggambaran secara grafik agar lebih mudah dilakukan pembahasan hasil dan dilakukan analisa lebih lanjut. Suhu udara rerata pada saat pengukuran yang dilakukan beberapa hari adalah mencapai $35,1^{\circ} \mathrm{C}$. Pada bata polos (tanpa perlakuan) pada suhu tersebut, suhu ruang dalam terukur mencapai $35,7^{\circ} \mathrm{C}$. Pembahasan dimulai dengan perlakuan profil secara horizontal dengan keberagaman dimensi perlakuan.

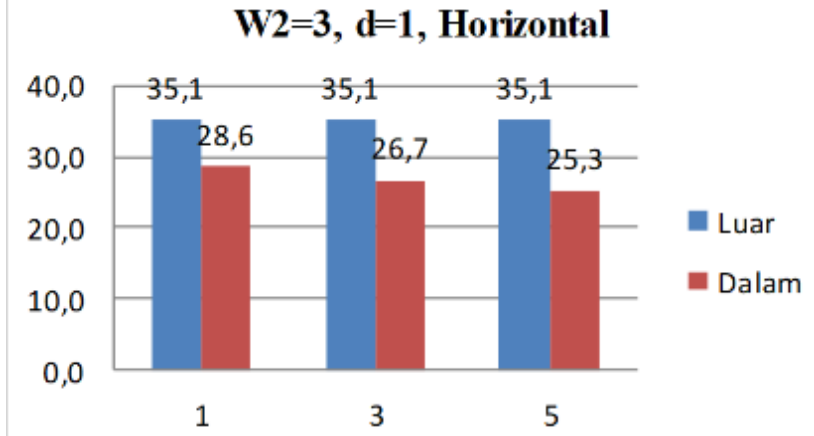

Gambar 4. Perlakuan $w 2=3, d=1$, profil horizontal (sumber: hasil analisis, 2017)

Grafik pertama pada gambar 4 menunjukkan bahwa pada bata ringan dengan ketebalan $7 \mathrm{~cm}$ dibuat profil lebar permukaan luar sebesar $3 \mathrm{~cm}$, kedalaman profil $1 \mathrm{~cm}$ dan lebar bagian dalam $1 \mathrm{~cm}, 3 \mathrm{~cm}$, dan $5 \mathrm{~cm}$. Dari grafik tersebut terlihat adanya penurunan suhu udara ruang dalam dari menjadi $28,6^{\circ} \mathrm{C}$ hingga $25,3^{\circ} \mathrm{C}$. Selisih suhu tertinggi terjadi pada perlakuan ketiga (w1 $=5 \mathrm{~cm}$ ) yaitu $9,8^{\circ} \mathrm{C}$.

Grafik pada gambar 5 menjelaskan perlakuan lebar permukaan luar sebesar $5 \mathrm{~cm}$, kedalaman $1 \mathrm{~cm}$ dan lebar bagian dalam $1 \mathrm{~cm}, 3 \mathrm{~cm}$, dan $5 \mathrm{~cm}$. Grafik tersebut menunjukkan rerata hasil pengukuran suhu ruang dalam yang hampir sama dari $26,8^{\circ} \mathrm{C}$ pada $w 1=1 \mathrm{~cm}, 27,30 \mathrm{C}$ pada $w 1=3 \mathrm{~cm}$ dan $26,9^{\circ} \mathrm{C}$ pada $\mathrm{w} 1=5 \mathrm{~cm}$. Selisih terbesar terjadi pada perlakuan pertama $(\mathrm{w} 1=1 \mathrm{~cm})$ yaitu sebesar $8,3^{\circ} \mathrm{C}$.

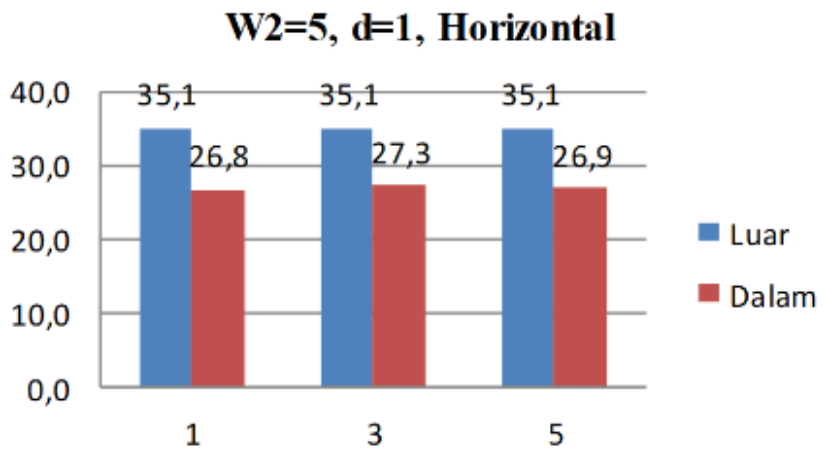

Gambar 5. Perlakuan w2=5, $d=1$, profil horizontal (sumber: hasil analisis, 2017)

Grafik pada gambar 6 masih hasil pengukurann pada bentuk profil horizontal dengan lebar permukaan luar sebesar $3 \mathrm{~cm}$ dan kedalaman hingga $3 \mathrm{~cm}$. Sama seperti perlakuan bata sebelumnya, lebar bagian dalam (w1) adalah sebesar $1 \mathrm{~cm}, 3 \mathrm{~cm}$, dan $5 \mathrm{~cm}$. Berdasar pengukuran yang dilakukan, data suhu yang didapatkan adalah $27,1^{\circ} \mathrm{C}$ pada $w 1=1 \mathrm{~cm}, 29,6^{\circ} \mathrm{C}$ pada $w 1=3 \mathrm{~cm}$, dan $31,1^{\circ} \mathrm{C}$ pada $w 1=5 \mathrm{~cm}$. Hal ini menunjukkan adanya peningkatan suhu udara ruang dalam seiring semakin lebarnya lebar pada bagian dalam. Selisih suhu udara terbesar terjadi pada perlakuan $w 1=1 \mathrm{~cm}$ yaitu hingga $8^{\circ} \mathrm{C}$. 
$\mathrm{W} 2=3, \mathrm{~d}=3$, Horizontal

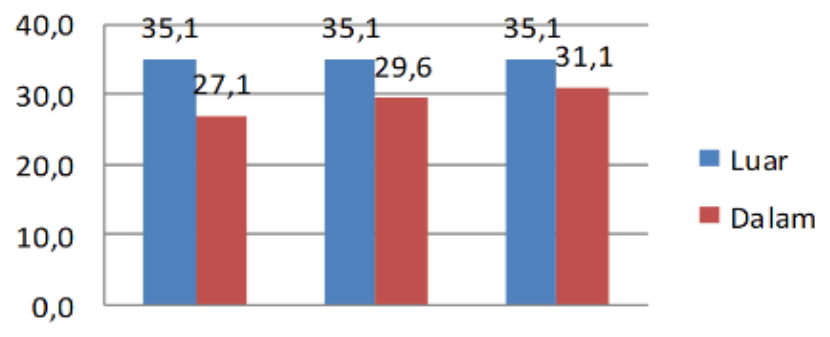

13

Gambar 6. Perlakuan $w 2=3, d=3$, profil horizontal (sumber: hasil analisis, 2017)

Rekayasa yang diterapkan pada eksperimen kali ini adalah dengan lebar bagian permukaan luar (w2) sebesar $5 \mathrm{~cm}$ dan kedalaman $3 \mathrm{~cm}$ dengan varian lebar bagian dalam $1 \mathrm{~cm}, 3 \mathrm{~cm}$ dan $5 \mathrm{~cm}$. Pembayangan terlihat cukup jelas pada eksperimen ini. Grafik pada gambar 7 menunjukkan penurunan suhu antara suhu ruang luar dan ruang dalam dengan selisih penurunan $4,8^{\circ} \mathrm{C}$ hingga $5,7^{\circ} \mathrm{C}$. Penurunan terbesar terjadi pada perlakuan lebar bagian dalam sebesar $1 \mathrm{~cm}$ yaitu dari $35,1^{\circ} \mathrm{C}$ menjadi $29,4^{\circ} \mathrm{C}$.

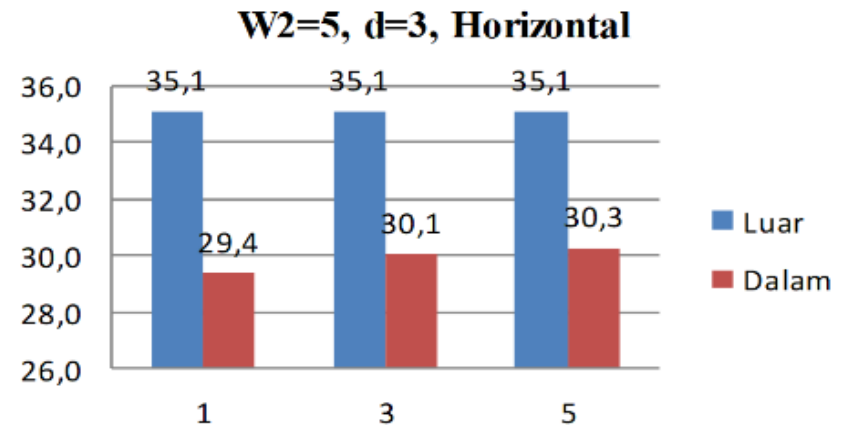

Gambar 7. Perlakuan w2=5, d=3, profil horizontal (sumber: hasil analisis, 2017)

Pembahasan berikutnya adalah terhadap eksperimen dengan perlakuan profil permukaan bata ringan berbentuk vertikal. Perlakuan antara permukaan bagian luar, dalam dan kedalaman sama dengan bata dengan profil horizontal.pengukuran suhu udara juga dilakukan di ruang luar (terbuka) dan ruang dalamnya.

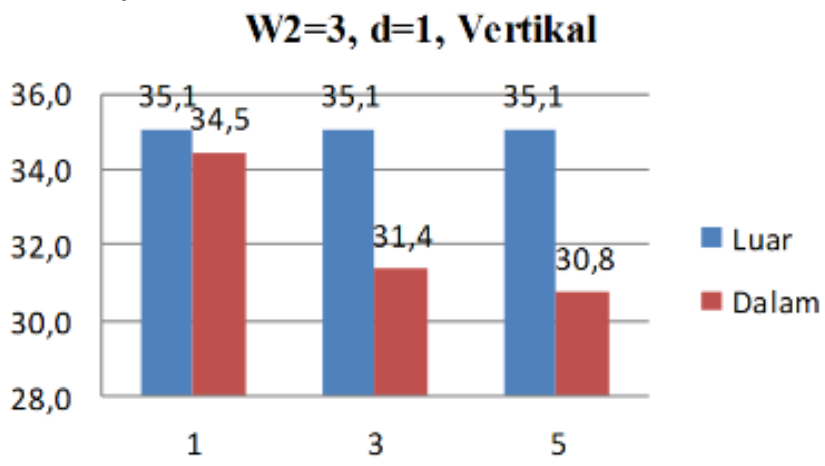

Gambar 8. Perlakuan $w 2=3, d=1$, profil vertikal (sumber: hasil analisis, 2017)
Perlakuan bentuk profil permukaan bata ringan vertikal yang diterapkan yang dibahas pertama adalah dengan lebar permukaan bagian luar sebesar $3 \mathrm{~cm}$ dan kedalaman $1 \mathrm{~cm}$. Pada gambar 8 menunjukkan penurunan suhu terbesar hingga menjadi $30,8^{\circ} \mathrm{C}$ dari $35,1^{\circ} \mathrm{C}$ pada suhu ruang luar atau selisih $4,3^{\circ} \mathrm{C}$. Penurunan suhu juga terlihat seiring dengan semakin lebarnya permukaan dalam bata ringan tersebut. Pembayangan terjadi sedikit karena kedalaman yang hanya $1 \mathrm{~cm}$ serta posisi yang vertikal.

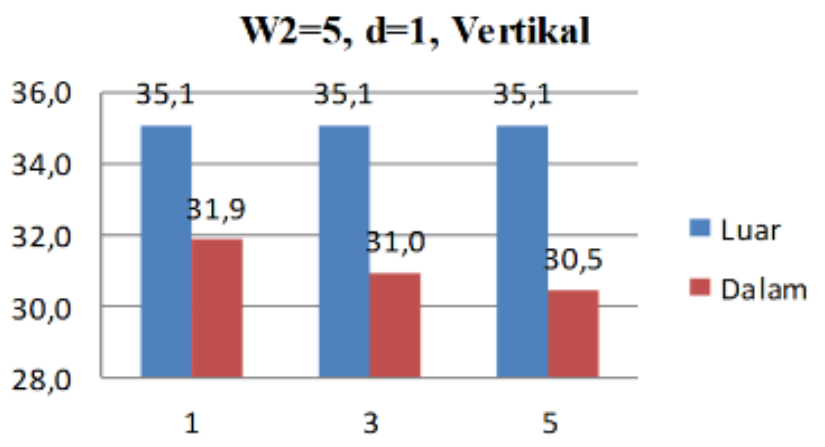

Gambar 9. Perlakuan $\mathrm{w} 2=5, \mathrm{~d}=1$, profil vertikal (sumber: hasil analisis, 2017)

Gambar 9 menunjukkan selisih penuruan antara bata dengan perlakuan $w 1=1 \mathrm{~cm}, w=1=3 \mathrm{~cm}$, serta $w 1=5$ sangat kecil yaitu kurang dari $1^{\circ} \mathrm{C}$ antar perlakuan tersebut. Penurunan suhu ruang dalam terlihat semakin membesar seiring dengan lebar sisi sebelah dalam bata ringan tersebut, setidaknya hingga lebar $5 \mathrm{~cm}$. Penurunan terbesar terjadi pada $w 1=5 \mathrm{~cm}$ yaitu sebesar $4,6^{\circ} \mathrm{C}$.

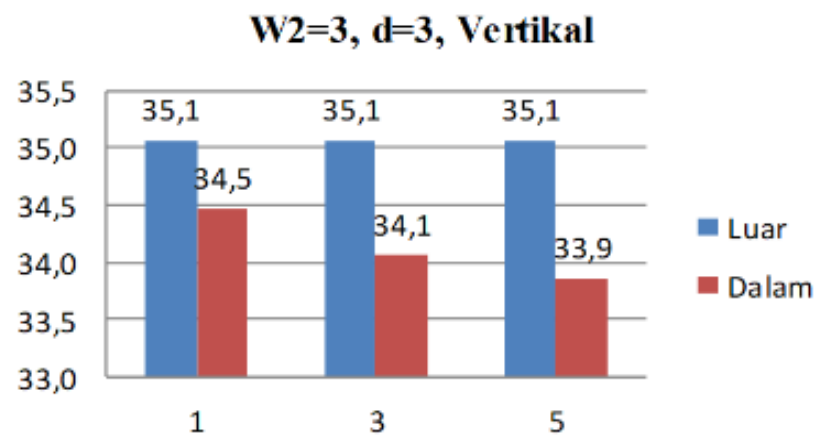

Gambar 10. Perlakuan w2=3, d=3, profil vertikal (sumber: hasil analisis, 2017)

Perlakuan selanjutnya terlihat pada gambar 10 yaitu dengan membentuk profil permukaan bata lebar bagian luar (w2) sebesar $3 \mathrm{~cm}$, kedalaman (d) $3 \mathrm{~cm}$ dan lebar bagian dalam (w1) sebesar $1 \mathrm{~cm}, 3 \mathrm{~cm}$ dan $5 \mathrm{~cm}$ serta posisi lis profil vertikal terhadap permukaan tanah. Data yang didapatkan dari perlakuan tersebut adalah terjadi penurunan suhu menjadi $34,5^{\circ} \mathrm{C}$ dengan $\mathrm{w} 1=1 \mathrm{~cm}, 34,1^{\circ} \mathrm{C}$ dengan $\mathrm{w} 1=3 \mathrm{~cm}$ dan $33,9^{\circ} \mathrm{C}$ dengan $\mathrm{w} 1=5 \mathrm{~cm}$. Selisih terbesar didapatkan pada perlakuan $w 2=3 \mathrm{~cm}, d=3$ dan $w 1=5 \mathrm{~cm}$, meski penurunannya juga tidak terlalu signifikan yaitu hanya sebesar $1,2^{\circ} \mathrm{C}$. 


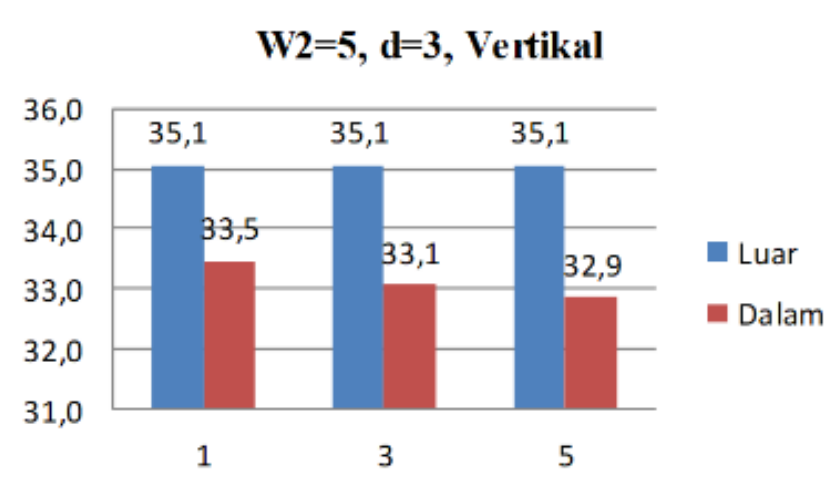

Gambar 11. Perlakuan $w 2=5, d=3$, profil vertikal (sumber: hasil analisis, 2017)

Hasil perlakuan terakhir terlihat pada gambar 11, yang menunjukkan terjadinya penurunan suhu udara dalam seiring dengan semakin melebarnya permukaan bagian dalam hingga $5 \mathrm{~cm}$ dibandingkan dengan lebar bagian luar yang juga $5 \mathrm{~cm}$. Mendekati pada perlakuan profil berbentuk vertikal lainnya, penurunan suhu yang terjadi juga tidak terlalu besar, namun setidaknya lebih besar dibandingkan dengan perlakuan kedalaman profil sebelumnya $(\mathrm{d}=1 \mathrm{~cm})$. Selisih terbesar terjadi pada perlakuan $\mathrm{w} 2=5 \mathrm{~cm}, \mathrm{~d}=3 \mathrm{~cm}$ dan $\mathrm{w} 1=5 \mathrm{~cm}$ yaitu sebesar $2,2^{\circ} \mathrm{C}$.

\subsection{Penelusuran penurunan temperatur ruang dalam}

Berdasarkan hasil pengukuran dan pembahasan, ada beberapa hal yang perlu dilakukan analisa lebih lanjut. Perlakuan bata dengan lebar sisi luar (W2) $3 \mathrm{~cm}$ dan kedalaman $1 \mathrm{~cm}$ dan $3 \mathrm{~cm}$ posisi horizontal memiliki perbedaan hasil kecenderungan temperatur. Semakin dalam profil ternyata menjadikan temperatur meningkat jika dimensi bagian dalam diperlebar.
Perlakuan optimal terjadi jika dengan kedalaman yang hanya $1 \mathrm{~cm}$ dan lebar bagian dalam mencapai $5 \mathrm{~cm}$. Kasus ini menjadikan dugaan bahwa pembayangan tidak mutlak mempengaruhi hasil pengukuran temperatur, mengingat bayangan terkuat seharusnya terjadi pada perlakuan kedalaman $3 \mathrm{~cm}$ dan lebar $1 \mathrm{~cm}$.

Berdasar hasil pengukuran hal tersebut memang terjadi, namun masih di atas dari kedalaman $1 \mathrm{~cm}$ dan lebar $5 \mathrm{~cm}$ yang memiliki pembayangan lebih kecil dibandingkan dengan perlakuan kedalaman $3 \mathrm{~cm}$ dan lebar bagian dalam $5 \mathrm{~cm}$. Perlakuan posisi profil vertikal, baik kedalaman $1 \mathrm{~cm}$ maupun $3 \mathrm{~cm}$ memiliki kecenderungan yang sama, yaitu semakin lebar bagian dalamnya, semakin rendah temperatur yang dihasilkan. Meski demikian, temperatur yang dihasilkan tidak serendah jika posisi horizontal.

Jika dicermati berdasar kondisi saat pengukuran, profil vertikal justru memiliki pembayangan yang minim pada siang hari namun besar pada saat pagi dan sore hari, sehingga dari hasil pengukuranpun tercatat temperatur rata-rata yang ada di atas $30^{\circ} \mathrm{C}$. Sudut pembayangan yang terbentuk pada profil permukaan bata yang telah dibentuk. Hal tersebut tidaklah seperti yang dihasilkan dengan posisi profil horizontal.

Masing-masing perlakuan terhadap profil bata ringan dikomparasikan untuk mempelajari hasilnya. Perbandingan awal guna mempermudah dilakukan pengelompokan berdasarkan dimensi lebar permukaan bagian luar. Hal ini dilakukan dengan pertimbangan luasnya area yang terpapar oleh radiasi panas matahari, karena hal ini paling besar pengaruhnya terhadap temperatur ruang dalam.
$\mathrm{W} 2=\mathbf{3}, \mathrm{d}=1$, Horizontal

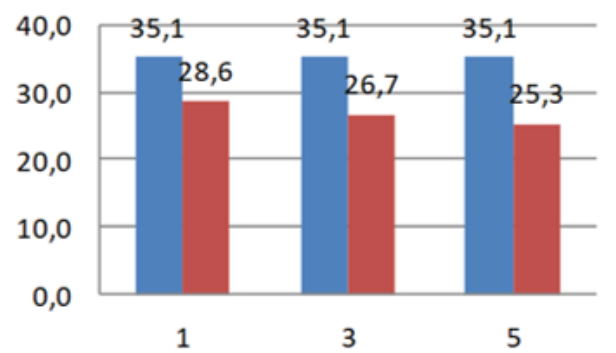

$\mathrm{W} 2=3, \mathrm{~d}=1$, Vertikal

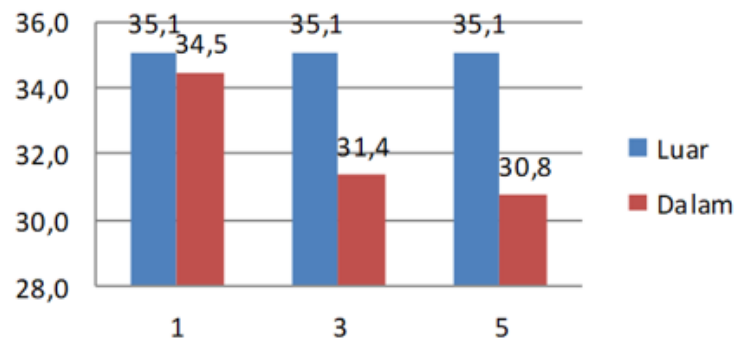

$W 2=3, d=3$, Horizontal
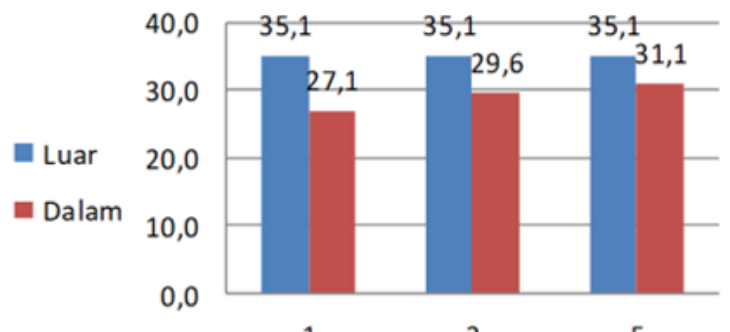

m Luar

Dalan

1

$W 2=3, d=3$, Vertika I

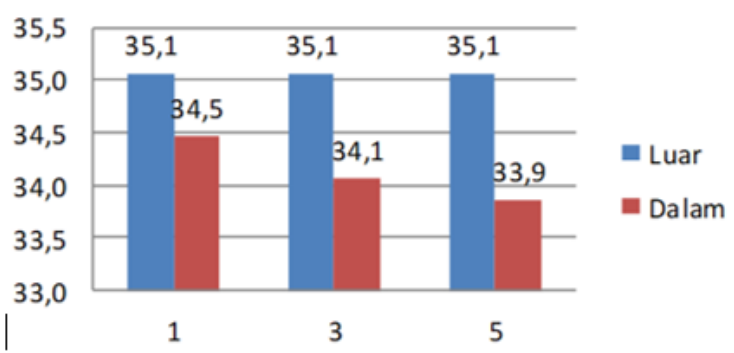

Gambar 12. Perlakuan dengan profil w2 $=3 \mathrm{~cm}$ (sumber: hasil analisis, 2017) 
$\mathbf{W}=5, \mathrm{~d}=1$, Horizontal

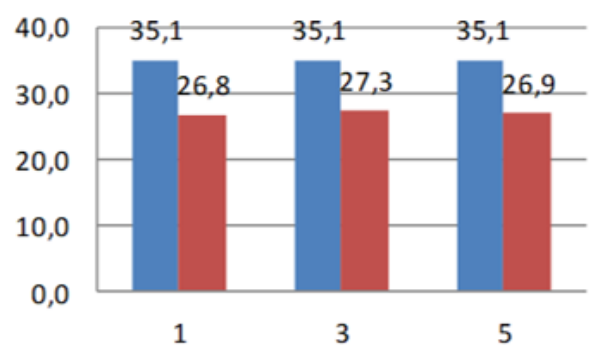

$W 2=5, d=1$, Vertikal

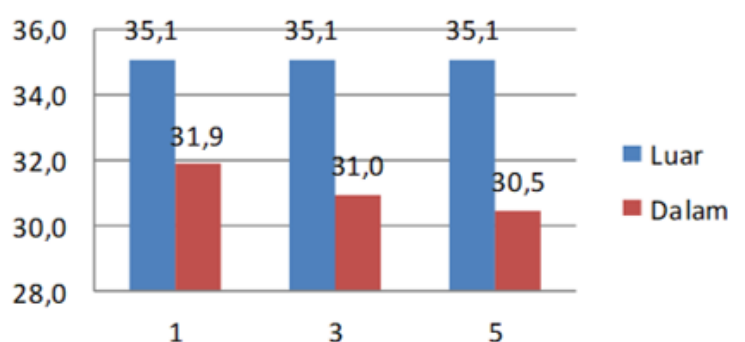

Gambar 13. Perlakuan dengan profil
Perlakuan berikutnya adalah dengan pembentukan dimensi bagian luar selebar $5 \mathrm{~cm}$ dengan kedalaman $1 \mathrm{~cm}$ dan $3 \mathrm{~cm}$ serta posisi profil horizontal dan vertikal. Posisi profil horizontal dengan kedalaman $1 \mathrm{~cm}$ dan $3 \mathrm{~cm}$ terlihat bahwa dengan kedalaman $1 \mathrm{~cm}$ justru didapatkan temperatur rata rata terendah, meskipun rata rata hasil dari pengukuran cenderung acak. Jika dilakukan analisa lebih dalam terhadap perlakuan $\mathrm{w} 2=3 \mathrm{~cm}$ dan posisi profil horizontal, maka didapatkan kecenderungan baik pada $d=1 \mathrm{~cm}$ maupun $d=3 \mathrm{~cm}$, semakin besar dimensi bagian dalam, maka semakin naik temperatur ruang dalam yang dihasilkan.

Seperti halnya pada $w 2=3 \mathrm{~cm}$, pada perlakuan $\mathrm{w}=5 \mathrm{~cm}$ dengan posisi profil vertikal dihasilkan temperatur yang semakin menurun jika lebar bagian dalamnya diperlebar. Hal ini bertentangan dengan perlakuan posisi profil horizontal. Perlakuan posisi profil vertikal menghasilkan pembayangan yang lebih kecil pada siang hari, namun besar pada pagi dan sore hari. Profil vertikal antara $d=1 \mathrm{~cm}$ dan $\mathrm{d}=3 \mathrm{~cm}$ memiliki kecenderungan rata rata temperatur udara ruang dalam yang lebih rendah dengan kedalaman $1 \mathrm{~cm}$.

Komparasi dari semua perlakuan terbukti bahwa ketebalan material memiliki pengaruh terhadap temperatur udara ruang dalam. Hal ini terlihat pada kedalaman profil $1 \mathrm{~cm}$ dibandingkan dengan kedalaman $3 \mathrm{~cm}$. Kedalaman $1 \mathrm{~cm}$ menyisakan ketebalan $6 \mathrm{~cm}$, sedangkan kedalaman $3 \mathrm{~cm}$ menyisakan ketebalan $4 \mathrm{~cm}$. Semakin tipis material terlihat menyebabkan rambatan panas ke bagian ruang dalam lebih mudah. Pada penelitian sebelumnya tentang perambatan termal pada material dinding menunjukkan bahwa bata ringan memiliki resistensi terhadap termal yang baik (Suhedi, 2014). Hal ini
$\mathrm{W} 2=5, \mathrm{~d}=3$, Horizontal

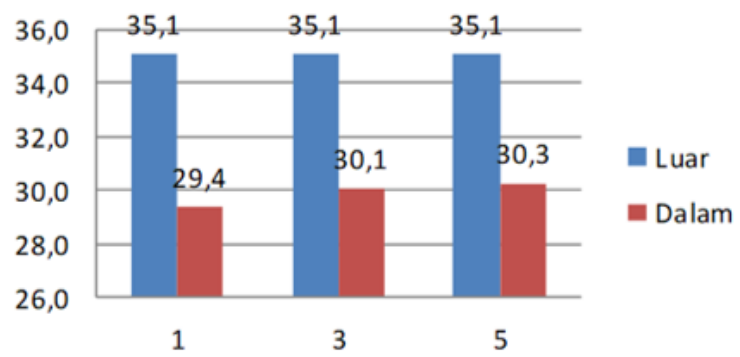

$W_{2}=5, d=3$, Vertikal

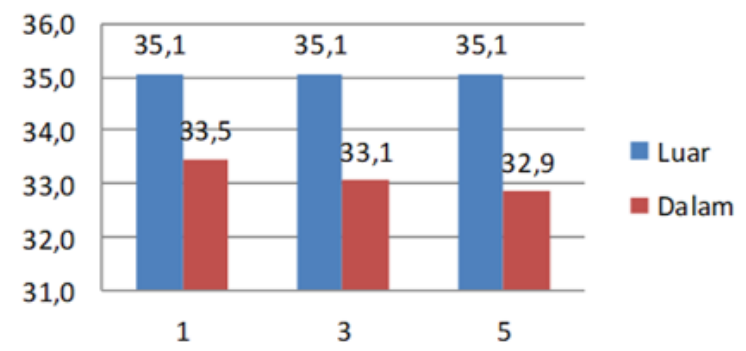

(sumber: hasil analisis, 2017)

semakin memperbaiki upaya penurunan termal ruang dalam, ketebalan material dinding juga berpengaruh terhadap hasil pengukuran.

Tabel 1. Komparasi hasil pengukuran

\begin{tabular}{ccccc}
\hline \multirow{2}{*}{$\begin{array}{c}\text { Permukaan } \\
\text { dalam }(\mathrm{cm})\end{array}$} & $\begin{array}{c}\text { permukaan } \\
\text { luar }(\mathrm{cm})\end{array}$ & $\begin{array}{c}\text { Kedalaman } \\
(\mathrm{cm})\end{array}$ & \multicolumn{2}{c}{$\begin{array}{c}\text { Suhu udara ruang } \\
\text { dalam }\left({ }^{\circ} \mathrm{C}\right)\end{array}$} \\
\cline { 4 - 5 } 1 & 3 & 1 & 28,6 & 34,5 \\
1 & 3 & 3 & 27,1 & 34,5 \\
1 & 5 & 1 & 26,8 & 31,9 \\
1 & 5 & 3 & 29,4 & 33,5 \\
3 & 3 & 1 & 26,7 & 31,4 \\
3 & 3 & 3 & 29,6 & 34,1 \\
3 & 5 & 1 & 27,3 & 31 \\
3 & 5 & 3 & 30,1 & 33,1 \\
5 & 3 & 1 & 25,3 & 30,8 \\
5 & 3 & 3 & 31,1 & 33,9 \\
5 & 5 & 1 & 26,9 & 30,5 \\
5 & 5 & 3 & 30,3 & 32,9 \\
\hline
\end{tabular}

Sumber: Hasil analisis 2017

Posisi profil vertikal dengan perlakuan dimensi bagian dalam semakin lebar memiliki pengaruh menurunkan temperatur udara di ruang dalam, hal ini diduga terjadi karena bagian yang terbayangi dari sinar matahari di pagi dan sore hari lebih lebar. Hal ini sejalan dengan pada perlakuan profil dengan posisi horizontal, semakin sempit dimensi lebar bagian dalam profil dan dengan lebar profil bagian luar yang juga sempit akan menurunkan temperatur udara ruang dalamnya. 


\section{KESIMPULAN}

Beberapa kesimpulan yang dapat ditarik dari pengkajian ini yang berkaitan dengan bentuk profil permukaan bata ringan terhadap perubahan temperatur ruang dalam bahwa ketebalan bata ringan (ketebalan bata ringan dikurangi kedalaman profil) mempengaruhi perbedaan dampak radiasi panas matahari dari ruang luar menuju ke ruang dalam. Selain itu pembentukan profil pada permukaan bata ringan dapat menurunkan temperatur ruang dalam lebih dari (minimal) $2^{\circ} \mathrm{C}$. Pembayangan juga akan lebih efektif jika bentuk profil adalah vertikal, karena memperkecil peluang terjadinya penyinaran radiasi panas matahari.

Adanya beberapa hal pengkajian lebih lanjut berkaitan dengan bata ringan terhadap perubahan temperatur ruang dalam, diantaranya adalah adanya dugaan faktor selain pembayangan yang mempengaruhi penurunan temperatur ruang dalam. Perlu juga dilakukan kajian lebih lanjut terhadap bata ringan berprofil pada ruang tertutup terhadap pengaruh hujan agar kelembaban bata ringan tetap terjaga sehingga tidak menambah kemungkinan penambahan variabel yang tidak terkendali, serta pengkajian terhadap bata ringan berprofil pada ruang tertutup terhadap pengaruh angin namun sinar matahari tetap leluasa mengenai objek. Kemudian juga harus dilakukan uji kekuatan bata ringan setelah dilakukan perubahan profil permukaan bata ringan.

\section{REFERENSI}

Dotulong, A. L. W. H. (2018). Pengaruh Pembayangan Massa Bangunan Terhadap Radiasi Panas Matahari Di Ruang Terbuka Kawasan Tropis Yang Terletak Pada Garis Lintang $7^{\circ}$ Ls. Jurnal Arsitektur \& Perencanaan, 3(1), 1-11.

Hilmy, M. (2016). Pengaruh Rongga Pada Dinding Batako Terhadap Suhu Ruang Dalam. Jurnal Teknik Sipil Dan Perencanaan, 16(1), 15-20.

Hunggurami, E., Bunganaen, W., \& Muskanan, R. Y. (2014). Studi Eksperimental Kuat Tekan dan Serapan Air Bata Ringan Cellular Lightweight Concrete Dengan Tanah Putih Sebagai Agregat. Jurnal Teknik Sipil, 3(2), 125-136.

Lechner, N. (2014). Heating, cooling, lighting: Sustainable design methods for architects. John wiley \& sons.

Murtomo, B. A. (2008). Studi Sistem Pembayangan Pada Rumah Minimalis Studi kasus pada Perumahan Mega Residence Semarang. Jurnal IImiah Perancangan Kota Dan Permukiman, 7(1), 11-18.

Pagalla, A. G., Thojib, J., \& Sudarmo, B. S. (2013). Visualisasi Pola Pembayangan Pada Sentra Niaga Swarga Bara Di Sangatta, Kalimantan Timur (Skripsi). Universitas Brawijaya, Malang. Retrieved from http://arsitektur.ub.ac.id/visualisasi-pola- pembayangan-pada-sentra-niaga-swarga-bara-disangatta-kalimantan-timur/

Prakoso, N. A., Lamahala, A. K., \& Sentanu, G. (2014). Kajian Penerapan Material pada Selubung Bangunan yang Mempengaruhi Kenyamanan Termal dan Visual. REKA KARSA, 2(2). doi:10.26760/rekakarsa.v2i2.462

Rampanelli, G., Zardi, D., \& Rotunno, R. (2004). Mechanisms of Up-Valley Winds. Journal of the Atmospheric Sciences, 61(24), 3097-3111. doi:10.1175/JAS-3354.1

Saito, Y., Kanematsu, K., \& Matsui, T. (2009). Measurement of Thermal Conductivity of Magnesia Brick with Straight Brick Specimens by Hot Wire Method. MATERIALS TRANSACTIONS, $50(11)$, doi:10.2320/matertrans.M2009098 2623-2630.

Suhedi, F. (2014). Pengukuran Resistansi Termal Bahan Bangunan dengan Metode Aliran Kalor dalam Lingkungan Terkondisi. Jurnal Permukiman, 9(3), 169-180. doi:10.31815/jurnalkim.v9i3.54

Susanto, E. P., Soemardi, B. W., \& Pane, I. (2011). Studi Penggunaan Dinding Foam Concrete (FC) dalam Efisiensi Energi dan Biaya untuk Pendinginan Udara (Air Conditioner). Jurnal Teknik Sipil ITB. 